\title{
Thermal Performance and Degradation of Urea as a Result of Time and Storage Location
}

\author{
João Paulo Turmina ${ }^{1}$, Flávio Gurgacz ${ }^{1}$, Anderson Lenz ${ }^{1} \&$ Doglas Bassegio $^{1}$ \\ ${ }^{1}$ Graduate Program in Energy Engineering in Agriculture, State University of West Paraná, Cascavel, Brazil \\ Correspondence: João Paulo Turmina, Graduate Program in Energy Engineering in Agriculture, State University \\ of West Paraná (UNIOESTE), RuaUniversitária, 2069-JardimUniversitário, CEP 85819-110, Cascavel, Paraná \\ Brazil. Tel: 55-(45)-98826-1729. E-mail: arqjpt@gmail.com
}

Received: September 20, 2020

Accepted: November 6, 2020

Online Published: November 15, 2020

doi:10.5539/jas.v12n12p177

URL: https://doi.org/10.5539/jas.v12n12p177

\begin{abstract}
This research aims to analyze the degradation of urea in its storage process, observing the environmental conditions of the storage building and also the storage time. In order to carry out such analysis, a field experiment with a completely randomized design (CRD), $3 \times 4$, was set up, with eight $50 \mathrm{~kg}$ bags divided in four different locations, being a shed, an underground basement, and two reduced models built in wood, where one received thermal input minimization treatments and the other with simplified coverage and closings. Within the four environments, temperature (DBT) and temperature (WBT) were measured, where it was possible to obtain the relative humidity values enabling thus crossing the internal climatic data with the process of urea degradation in storage for a period of three months. To analyze urea degradation, the analytical manual of fertilizers of the Ministry of Agriculture (MAPA) was used. The analyses of the physicochemical parameters of nitrogen content, density, humidity, total bag weight, and also granulometry were carried out monthly. The data were validated by one (ANOVA) and Tukey test with 5\% probability of error. The results show that the environments with higher temperatures had a higher volatilization of nitrogen, the losses reached about $13 \%$ during the evaluated period. Losses of up to $5.3 \%$ of the density of the analyzed samples were also observed. In relation to the initial weight of the bags, losses totaled a reduction of $1.5 \%$. It was also possible to conclude that the lowest losses were recorded in places where there was greater ventilation during the day, where the thermal inertia of the building dissipated.
\end{abstract}

Keywords: degradation, density, granulometry, humidity, hygroscopicity, nitrogen content, storage, urea, weight

\section{Introduction}

According to Contreiras et al. (2008), agriculture is an activity of great importance for the subsistence of the population, and since it is an activity that deals with natural resources, it must be carried out with sustainable conduct, aiming at the correct and efficient use of available natural resources, such as water, soil, minerals and so on. However, it is often necessary for agriculture to use extra energy resources to meet its physiological needs. In this sense, urea is largely responsible for replenishing much of the nitrogen deficits for most crops. Such an input, in most cases, is obtained from chemical reactions between minerals. Thus, there is a safe dose for the use of this resource without any risk to the environment. However, urea is extremely sensitive to climatic hostilities, and often it is affected, which is why it loses its quality and efficiency.

The problem is caused by improper handling during storage, in which the raw materials are often stored in inappropriate conditions. Thus, this research aims to respond to the provocations of nitrogen conservation in the agricultural urea research focus and also to dimension its losses as a result of the storage environment and the time.

To investigate, and in an attempt to follow the degradation path of urea grains, this search will seek theoretical support from works that directly or indirectly observed urea commercialized in Brazil, the so-called commercial urea.

In this sense, Alcade et al. (1992) evaluated the hygroscopicity of fertilizers and correctives, seeking to analyze the amount of water absorbed by simple fertilizer mixtures as a function of environmental humidity and exposure time. In conclusion, water was absorbed by the products as the relative humidity of the air, and the exposure time increased. 
As noted by Carvalho (1995), segregation can be defined as the physical separation of some granules and constitutes the main cause of the lack of uniformity for some inadequately prepared mixtures. However, each grain has its composition, sometimes it is not possible to have a sample uniformity among all the granules from the same group, and according to the author's reports, this lack of uniformity may disfigure a sample.

According to Alcade et al. (1992), such a process is also detrimental to the application of fertilizer in the field, as there is no guarantee that the nutrient will reach the correct dosage distribution in the soil. The authors emphasize that there may be mutations in the volume of the granule; this factor is a disadvantage to the application uniformity due to hygroscopicity.

According to Bono et al. (2008), the urea segregation processes are mineralization, nitrification, denitrification, leaching, and volatilization, which is the largest responsible for the loss of $\mathrm{N}$, which occurs through the volatilization of ammonia gas $\left(\mathrm{N}-\mathrm{NH}_{3}\right)$ after chemical reactions related to the exposure environment.

In this sense, Tasca et al. (2011), seeking to quantify the differences in the volatilization time of $\left(\mathrm{N}-\mathrm{NH}_{3}\right)$ conventional urea, observed the urea urease time over different forms of application, one is applied on the soil and the other, incorporated into the substrate, thus realizing that incorporated urea is rapidly hydrolyzed by soil organic matter, which is why the substance has its $\mathrm{PH}$ elevated and ending in the volatilization of $\left(\mathrm{N}-\mathrm{NH}_{3}\right)$, the process by which urea volatilizes nitrogen into the atmosphere.

Still analyzing this process, the authors submitted samples in a temperature-controlled environment, at a range of $18{ }^{\circ} \mathrm{C}$ and $35^{\circ} \mathrm{C}$, in which it is possible to observe that the volatilization peak occurs in the first week after the application; they also observe modifications due to temperature increase in which the process apparently accelerates.

Urea is an agricultural input that has been widely used, however, from the moment of purchasing the product until its use, it can suffer a degradation process, and may lose part of its physical and chemical properties, which is detrimental for its performance. Therefore, as a way of observing how such a degrading process occurs, this research simulated, through a field experiment, the storage of the input under four different conditions for three months, and thus obtained the losses values according to the time and place of storage.

In addition, a hypothesis level approach was also performed regarding the physical element responsible for the degradation of urea, in order to confirm hypotheses that, for example, the temperature and relative air humidity are the triggers of phenomena related to the loss of physical and chemical properties, such as ammonia volatilization and the granule clumping and agglutination.

A second analysis was also performed regarding the thermal performance of buildings and the efficiency of the environmental comfort treatments as a function of the materials, the incident insolation, and the mechanisms of shading and thermal lag.

\section{Method}

\subsection{Location}

The experiments were conducted on the campus of the Western Paraná State University (UNIOESTE), located southwest of the city, at latitude and longitude $24^{\circ} 59^{\prime} 16^{\prime \prime} \mathrm{S}$ and $53^{\circ} 26^{\prime} 55^{\prime \prime} \mathrm{W}$, in a relatively peripheral region of Cascavel-PR.

\subsection{Environment Treatments}

In order to simulate different environmental conditions and their consequences in the physical-chemical degradation of nitrogenates, a total of $400 \mathrm{~kg}$ of common urea was stored, subdivided into four environments:

Climatic model (CM): with a volume of approximately $0.85 \mathrm{~m}^{3}$, and treatments that aim to attenuate temperature exchanges with the external environment.

Non-climate model (NCM): a model with an environment of approximately $0.85 \mathrm{~m}^{3}$, without mechanisms to control temperature exchanges with the external environment, only with conventional seals, such as roofs, walls without wood and floor in naval plywood sheet.

Empirical garage model (EGM): a model built in masonry, similar to those that can be found in rural properties for the storage of agricultural machinery and inputs.

Empirical basement model (EBM): model built in masonry, semi-buried, also similar to buildings found in agricultural properties for storing materials and inputs. 
Each of these experimental units was equipped with a set of sensors for measuring temperature (Tbs/Tbu) and relative air humidity (\%). All the experimental units were subjected to the same local climatic variables (Figure $1)$.

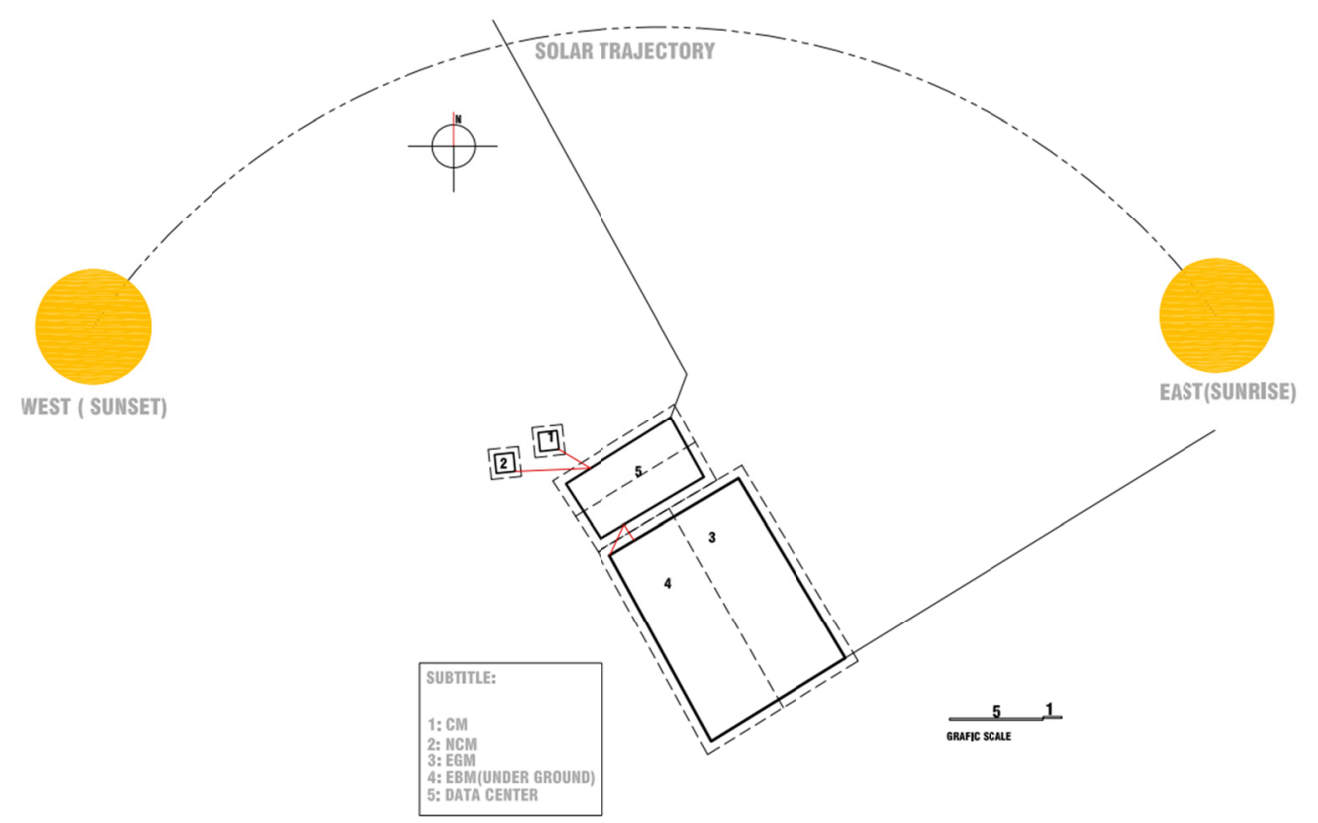

Fgure 1. Experimental field layout and situation of each experimental model

\subsection{Physicochemical Tests}

During the period of the field experiment, the physical and chemical mutations of the samples submitted to the experiment were analyzed individually, in each treatment (time and location), where the characteristics placed as desirable by the Ministry of Agriculture, Livestock and Food Supply (MAPA) (2014) were observed. The samples were inspected in terms of their nitrogen content, density, moisture content, total package weight, and granulometry, at the beginning and at the end of each month of the experiment.

\subsubsection{Nitrogen Content}

As previously reported, among the processes of degradation of urea there are phenomena related to volatilization of $\mathrm{N}_{-} \mathrm{NH}_{3}$, in which the granules lose their physicochemical properties. Such a process is expected when the nutrient is applied to the soil, so it is necessary that when the nutrient is applied the nutrient remains immobilized, as it will be mineralized in the soil.

In this sense, the research evaluated these losses by the analytical method of fertilizers and correctives, recommended by MAPA (2014), which determines that for analysis of samples containing urea or nitrogen in amidic and ammoniacal form, analysis by Raney alloy is not necessary, thus using the method of distillation with calcium hydroxide.

Embrapa (2013) evaluated two procedures for determining total nitrogen, one of which is referenced in the analytical methods of MAPA (2014), and found that the $\mathrm{N}$ contents declared on the packaging are equivalent to the values calculated in both methods performed in the research.

Samples submitted to the four storage models were analyzed, simultaneously subjected to the same climatic variables, where an initial analysis was carried out before submission to the experiment, as a way to obtain an initial characterization, as well as a periodic monthly evaluation. Also, at the end of each of the three months, laboratory analyzes were carried out in order to quantify the nitrogen in the sample in order to obtain monthly losses.

\subsubsection{Density}

To analyze the disintegration process of urea subjected to the proposed treatments, analyzes of the density of each sample were carried out, verifying the physical changes, by the method determined by Mialhe, Milan, and Gadanha (1996), according to Equation (1). Such method consists in filling a container with a known volume to 
the top with the granules, and then weighing them with $0.01 \mathrm{~g}$ analytical precision and calculating according thefollowing equation:

$$
d=M s / t v
$$

Where, $\mathrm{d}=$ density; $\mathrm{Ms}=$ mass in $\mathrm{g}$; $\mathrm{tv}=$ total volume in $\mathrm{m}^{3}$.

According to Feltran et al. (2006), the quality of the fertilizer is influenced by its physical characteristics, namely density, size, shape, cohesion, angle of rest, consistency, and fluidity of the particles.

The authors also state that the displacement of the machine during the distribution of the fertilizer and the very collision with the distribution equipment can prevent a uniform distribution of the nutrient in the soil. Thus, the nutrient reaches the soil physically altered, decreasing its performance.

\subsubsection{Moisturecontent}

To analyze the amount of water absorbed by the samples, moisture analyzes were performed, as recommended by MAPA (2014). The method, which consists of weighing the samples before and after submitting them in an oven at $65^{\circ} \mathrm{C}$, to obtain the percentage of water absorbed by the samples, was calculated using Equation (2):

$$
M=\{[(W w-D w)] / D w\} \times 100
$$

Where, $\mathrm{M}=$ moisture in (\%); $\mathrm{Ww}=$ wet sample weight in $\mathrm{g} ; \mathrm{Dw}=$ dry sample weight in $\mathrm{g}$.

This analysis, as well as the analyses belonging to the group of physicochemical aspects, was also performed before the experiment and at the end of each month of the observed period, thus enabling a monthly parameter of the behavior of the fertilizer regarding its hygroscopy in the storage process.

It is also worth recommending that this isolated analysis can also respond to the effectiveness of the packaging in which the urea is distributed by the manufacturers.

Regarding the problems generated by exposure to critical levels of relative humidity, Alcade et al. (1992) state that the excess moisture in the granules will affect the quality of the fertilizer, with regard to fluidity and the resulting hardening.

\subsubsection{Weight}

The weight can be understood as one of the indications of nutrient losses and physical mass of urea. Therefore, to identify how much this variable is modified in the stored fertilizer, weighing of the bags subjected to the experiment was carried out, with an initial weighing and monthly monitoring of the total weight of one of the samples. It is important to note that care was takento keep the substance with the packaging closed throughout the experiment.

To obtain the values, a bench scale with a maximum capacity of $60 \mathrm{~kg}$ and a load reading with three decimal places without rounding was used.

\subsubsection{Granulometry}

According to Stafanato and Goulart (2013), the granulometry is directly related to the shape and size of the granules, thus the importance of preserving particle integrity is based on the fact that the subdivision of the material increases its surface area of exposure by mass area.

The analyzes were performed following the procedures determined by Mialhe, Milan, and Gadanha (1996). The procedure consists in using superimposed sieves in decreasing order with 4000;2800; 2000; 1000; 710; 500; 0250; and $0125 \mathrm{~mm}$ openings,subjected to a sieve shaker for at least $5 \mathrm{~min}$. After the procedure, the content of each sieve must be weighed with an accuracy of $0.01 \mathrm{~g}$. The procedure is also equivalent to that described by MAPA (2014).

\subsection{Statistical Analysis}

The perform the statistical analysis, this research used the computer software Sisvar 5.6, developed by Federal University of Lavras (UFLA). Regarding the storage experiments that considered location and time, a variance analysis (ANOVA) and tukey means test with $5 \%$ probability of error were performed.

The experiments were distributed as follows, completely randomized design (CRD), with a $3 \times 4$ factorial design, which analyzed the physical-chemical parameters at the beginning and at the end of each month, for a total of tree months. The samples were subjected to four differente buildings. 


\section{Results}

The research results will be presented, discussed and analyzed from two points of view, the first being the thermal performance of the buildings and their interactions with the external environment and the second, analyzing the process of urea segregation during storage as a result of the time and the environment.

Thus, to be able to understand the interactions between the observed environments and the external climate, the maximum and minimum temperatures were averaged during the period of the field experiment as follows:

Table 1. Values of temperature and relative humidity from the region during the experiment period

\begin{tabular}{lllll}
\hline \multirow{2}{*}{ Period } & \multicolumn{4}{c}{ Averages of external climatic conditions } \\
\cline { 2 - 5 } & Maximum & Minimum & Daily average & Relativeumidity \\
\hline November & $27.69^{\circ} \mathrm{C}$ & $17.40{ }^{\circ} \mathrm{C}$ & $22.54{ }^{\circ} \mathrm{C}$ & $82.76 \%$ \\
December & $29.59^{\circ} \mathrm{C}$ & $18.93{ }^{\circ} \mathrm{C}$ & $24.26{ }^{\circ} \mathrm{C}$ & $87.45 \%$ \\
January & $29.15^{\circ} \mathrm{C}$ & $17.73{ }^{\circ} \mathrm{C}$ & $23.44{ }^{\circ} \mathrm{C}$ & $77.97 \%$ \\
\hline
\end{tabular}

Source: Adapted from Simepar (2019).

According to the values in Table 1 it was possible to observe a typical summer in the western region of Paraná, where the climate is defined according to the Köppen classification as Cfa-subtropical climate, with hot summers, the average temperature of the hottest months being above $22{ }^{\circ} \mathrm{C}$, and the average temperature of the coldest month being below $18{ }^{\circ} \mathrm{C}$.

With the definition of the external temperature averages, it was possible to analyze the thermal performance of each of the environments observed in this research. In order to obtain the worst situation, concerning the external/interior integer, the maximum temperatures measured were used (Table 1).

Considering such performance simulation, it is possible to conclude that it is the building designer's responsibility to do the reverse-path at the moment of the specification of the materials and the sealings, recommending to organize the project in such a way that the facades that most gain/retain heat can be distributed in the guidelines where there will be factors that can reduce the heat flow.

\subsection{Thermal Flow of Buildings}

The study of the thermal flow consists of balancing the incident energy by the external climatic conditions and its integers with the internal climatic conditions. Thus, we calculated the flows according to the mathematical model presented by Lamberts, Dutra, and Pereira (2014) and ABNT (2003).

The results obtained were calculated based on the differences in temperature between outdoor and indoor, added to the contributions of external factors, such as irradiation (I), external surface resistance (rse), the relationship between absorbency and reflectivity $(\alpha+p=1)$ of the surface color, added to the variation in outdoor (maximum monthly) and indoor (average monthly) temperatures.

The evaluation of the thermal performance, according to ABNT (2003), can be performed during the design phase and after the execution. About the constructed building, the evaluation can be performed through on-site measurement, while in the design phase a computational simulation can be performed or using the information contained in a TRY-climatic reference year from a nearby city.

Below are described the values of heat losses and gains suffered by buildings during the field experiment, throughout November, December and January, between the years 2018/2019. The buildings had the following thermal performance, organized by facades of incidence: 
Table 2. Thermal flow given in watt $/ \mathrm{m}^{2}{ }^{\circ} \mathrm{C}$ obtained with the data collected in November

\begin{tabular}{lllll}
\hline November (Summer Solstice) & & & & \\
\hline Façade & EGM & EBM & NCM & CM \\
\hline North & -6.93 & 9.97 & -13.59 & -0.588 \\
South & 21.92 & 18.87 & 12.58 & 30.000 \\
East & -0.05 & -2.19 & -13.59 & -0.588 \\
West & -6.9 & -9.10 & -13.59 & -0.588 \\
Roof & 35.21 & 11.47 & 68.01 & 24.576 \\
\hline$\Delta \mathbf{t}(\mathbf{e x t} /$ int) Average & $1.6^{\circ}$ & $2.2^{0^{-}}$ & 3.1 & 2.04 \\
\hline
\end{tabular}

Note. ${ }^{*}$ The values used for calculation were obtained in Frota (2004).

It was observed during November that there were heat losses in at least three facades of each of the environments, and it was also possible to notice that during the summer the facades located to the south had a significant heat input, which can be explained because in summer the times of southeast (east) and southwest (west) sun are those when the sun falls at a virtually perpendicular angle to the facade and in this position the sun heats the surface of the material.

This reaction was expected and can be explained by the solar diagram of latitude $23^{\circ}$ South. The horizontal lines represent the trajectory of the sun in relation to the terrestrial plane, while the vertical lines represent the hour. Thus, it is possible to observe that in a good part of the summer months there is southeast and southwest insolation. As these peaks of solar irradiation happen at more extreme times, dawn and dusk, this allows the building to retain heat, causing them to remain warmer during the early hours of the night.

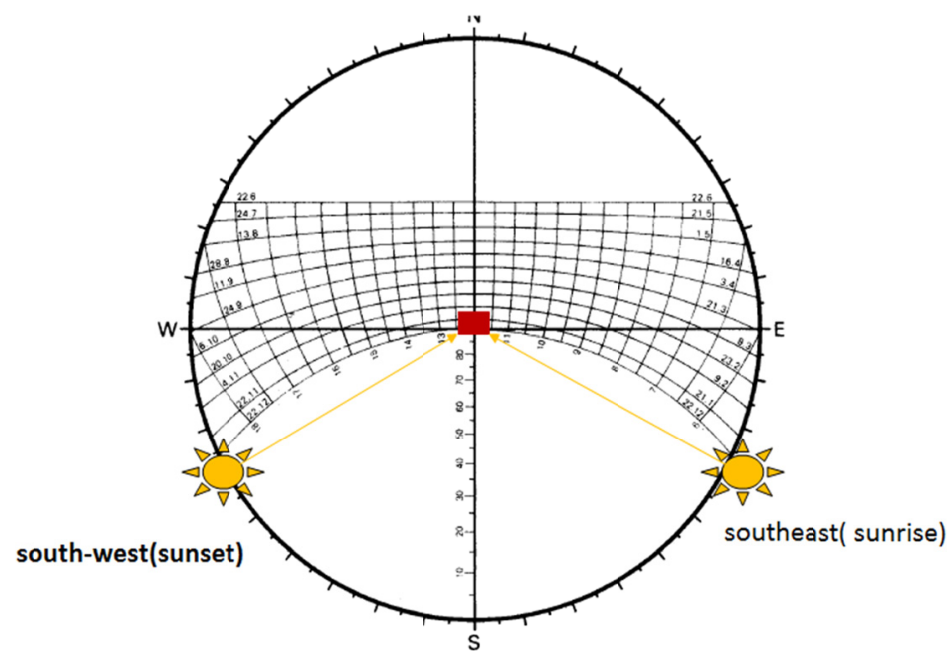

Figure 2. Solar chart from latitude $23^{\circ}$ South

Source: Adapted from Frota (2004).

In December, there was no great variation in relation to November, but the northern facade begins a cycle of loss, possibly because the sun was more present in the southern facade, causing the northern facade to be cooled by its shading in the most extreme hours (dawn and dusk), as the facade received sun again when it was higher in the sky, that is, close to the 12 o'clock incidence. 
Table 3. Thermal flow given in watt $/ \mathrm{m}^{2}{ }^{\circ} \mathrm{C}$ obtained with the data collected in December

\begin{tabular}{lllll}
\hline December (Summer Solstice) & & & & \\
\hline Façade & EGM & EBM & NCM & CM \\
\hline North & -9.88 & 18.87 & -20.54 & -24.29 \\
South & 18.98 & 4.09 & 5.64 & 6.29 \\
East & -9.88 & -15.26 & -20.54 & -24.29 \\
West & -9.88 & -15.26 & -20.54 & -24.29 \\
Roof & 34.32 & 9.88 & 52.27 & 13.01 \\
\hline$\Delta$ t(ext/int) Average & 2.2 & 3.1 & 4.52 & 4.57 \\
\hline
\end{tabular}

Note. * Material resistance values were obtained from Frota (2004).

In January, the average external temperature decreases, modifying the dynamics of the thermal flow. The losses of the north facade decrease in quantity, however, they remain negative, this characteristic will cause the buildings to retain more heat, which is desirable, because when the external temperature is lower, there will be greater ambiance and, therefore, comfort inside the building.

Table 4. Thermal flow given in watt $/ \mathrm{m}^{2}{ }^{\circ} \mathrm{C}$ obtained with the data collected in January

\begin{tabular}{lllll}
\hline January (Summer Solstice) & & & & \\
\hline Façade & EGM & EBM & NCM & CM \\
\hline Norte & -2.55 & -2.88 & -2.01 & -9.765 \\
Sul & 26.31 & 25.97 & 24.17 & 20.82 \\
Leste & -2.55 & -2.88 & -2.01 & -9.76 \\
Oeste & -2.55 & -2.88 & -2.01 & -9.76 \\
Cobertura & 37.13 & 13.60 & 94.23 & 24.025 \\
\hdashline $\mathbf{t}($ ext/int) Average & 0.9 & 0.96 & 0.84 & 2.1 \\
\hline
\end{tabular}

Note. * Material resistance values were obtained from Frota (2004).

After the thermal flow analysis, it was possible to note that the highest thermal flows in all three situations occurred on the buildings' roofs emphasizing and confirming the same hypothesis by Michels (2007), that roofs provide most of the heat input in buildings.

Other issues can be observed when analyzing the dynamics of the sun on buildings because the sun varies in position every hour, and this has great interference with the internal temperature.

In this sense, to be able to observe the differences between the behavior of the buildings, we selected the behavior of the four buildings during one day, measuring the temperatureevery hour, as it is possible to observe in the graphic (Figure3).

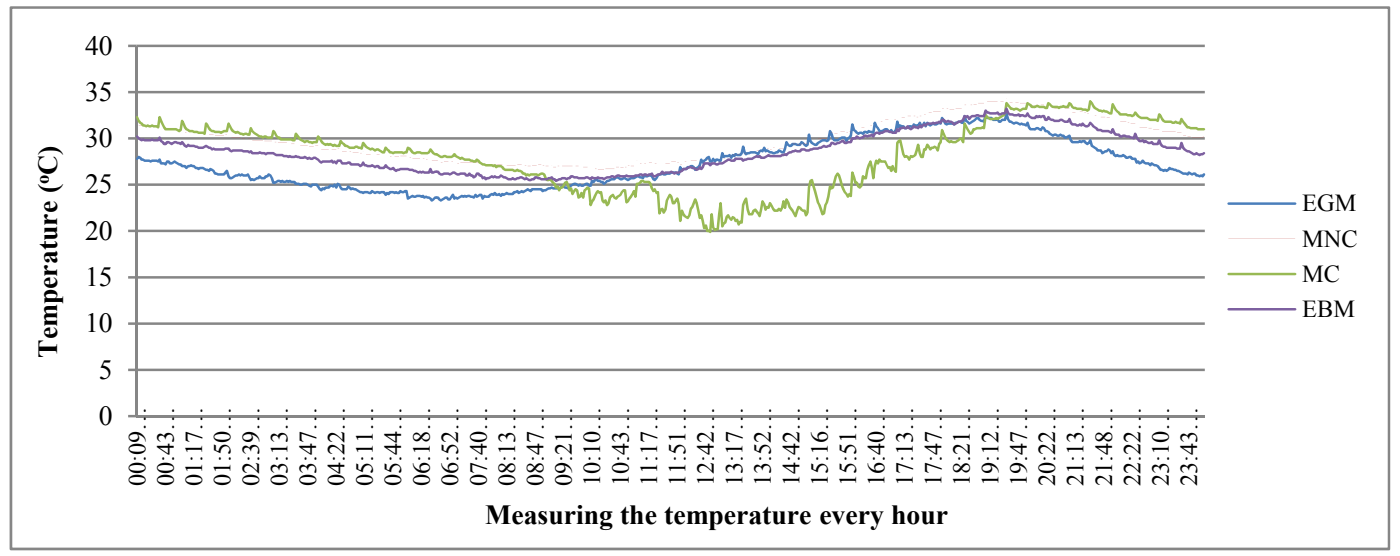

Figure 3. Daily temperature behavior in the experimental units 
In the graphic presented above it is possible to notice that there is some uniformity in the observed ambient temperatures, however, in the climatic model $(\mathrm{CM})$ after 09:00 am to 20:00 pm, the temperatures of this model (CM) decrease below the range of $25.0^{\circ} \mathrm{C}$ (averaged human comfort zone) and it is at this time that there is great intensity in the solar radiation. Before this time, the buildings are conserving heat. Comparing the final temperature between $\mathrm{NMC}$ and $\mathrm{CM}$, the $\mathrm{CM}$ had a better performance, because it could maintain a milder temperature inside, diverging from the NMC model that has a warmer environment during practically the whole day.

It was also observed a decrease of heat in the shed (EGM), this phenomenon occurred possibly due to the loss of heat by ventilation, as the building has a large right foot the heat can dissipate faster or be lost to the outside environment.

Note that in the basement environment (EBM) the temperature remains constant for most of the day and below the $30.0^{\circ} \mathrm{C}$ range. This characteristic is because the building has a good part of its environment below ground level. This environment's specificity is the result of the construction on the upper floor, which has a role in cushioning the heat transmission.

ABNT (2003) organizes eight climatic zones in Brazil and within each one of them, building standards for two situations such as winter and summer, which are situations in which the building should respond with certain performance standards. Concerning climate zone three (Z3) (Table 5), it is the zone in which the models tested by this research are inserted.

Table 5. Building guidelines for climate zone 3-(Z3)

\begin{tabular}{lll}
\hline Surface & Summer & Winter \\
\hline Roof & - Light isolated & - Passive solar heating \\
Walls & - Allow cross ventilation & - Allow sunrise during winter \\
& - Heavy internal seals (thermalinertial) & \\
\hline
\end{tabular}

Source: Adapted from ABNT (2003).

In the investigated environments, the following temperature and relative humidity maximum average conditions were recorded; we calculated the averages by the maximum ones because it is these values that determine the thermal stress reported by the researchers.

Table 6. Monthly behavior of temperature and relative humidity during the experiment (average of maximums)

\begin{tabular}{|c|c|c|c|c|c|c|c|c|}
\hline \multirow{2}{*}{ Period } & \multicolumn{2}{|c|}{ MEG } & \multicolumn{2}{|c|}{ MEP } & \multicolumn{2}{|c|}{ MC } & \multicolumn{2}{|c|}{ MNC } \\
\hline & $\mathrm{T}^{\circ} \mathrm{C}$ & UR \% & $\mathrm{T}^{\circ} \mathrm{C}$ & UR \% & $\mathrm{T}^{\circ} \mathrm{C}$ & UR \% & $\mathrm{T}^{\circ} \mathrm{C}$ & UR \% \\
\hline November & $30.9^{\circ}$ & 75.75 & $30.0^{\circ}$ & 75.98 & $28.6^{\circ}$ & 74.01 & $31.4^{\circ}$ & 89.70 \\
\hline December & $32.3^{\circ}$ & 63.95 & $33.2^{\circ}$ & 84.08 & $35.5^{\circ}$ & 77.51 & $32.5^{\circ}$ & 81.74 \\
\hline January & $30.5^{\circ}$ & 74.82 & $30.5^{\circ}$ & 93.39 & $31.7^{\circ}$ & 82.08 & $30.4^{\circ}$ & 87.01 \\
\hline Total Average & 31.2 & $71.5 \%$ & 31.2 & $84.4 \%$ & 31.9 & $77.8 \%$ & $31.4^{\circ}$ & $86.1 \%$ \\
\hline
\end{tabular}

\subsection{Urea Degradation}

The results obtained through the experiment prove the urea fragility degree and its losses concerning the time and mineral storage location; within this approach, the losses of the physical-chemical characteristics of nitrogen fertilizers were analyzed.

As previously mentioned, urea follows standards in its manufacture; professionals expect such standards when the prescription occurs at the dose for a particular crop or culture. Once preserved when released into the soil, there will be a uniform distribution of the nutrient in the substrate.

\subsubsection{Nitrogen Content}

The nitrogen contents were observed at the beginning of the experiment and the end of each month; the samples were taken from the contents in the middle of the package avoiding the withdrawal of the granules closer to the closing valve of the package. 
Thus, the following variations were observed regarding the nitrogen content of the granules, through the analysis of total nitrogen regulated by MAPA (2014). The analyses were performed in quadruplicate by a water and food laboratory; the results were submitted to variance analysis and the Tukey test with $5 \%$ probability. Thus, the following variations were observed separately between the storage locations, being the highest averages for the EBM and CM treatments, such locations had the lowest accumulated temperature averages during the entire observation time, only the EBM had a higher average of relative humidity (Table 6).

It is possible to observe that nitrogen losses also occur as a function of storage time, losing $1.77 \%$ in November in relation to the initial observation; from the first to the second month it is possible to observe that the losses practically quadruple, reaching $9.2 \%$.

In this regard, it is worth noting that December is the month in which there is the highest maximum average temperature inside the environments (Table 7); the month in which urea has a lower loss is in January, in which the average temperature is the lowest in all the observed environments. Analyzing the value of $\mathrm{P}$ additionally, it is possible to conclude that the integration between location and time is statistically significant being $(\mathrm{P}<0.05)$.

Still observing the integration between the treatments time and location is possible to note the following dynamics in losses (Table 7).

Table 7. Location $\times$ time nitrogen content detail

\begin{tabular}{lllll}
\hline \multirow{2}{*}{ Time } & \multicolumn{4}{c}{ Location } \\
\cline { 2 - 5 } & EGM & EBM & CM & NCM \\
\hline Initial & $46.19 \mathrm{aA}$ & $46.19 \mathrm{aA}$ & $46.19 \mathrm{aA}$ & $46.19 \mathrm{aA}$ \\
November & $44.93 \mathrm{aB}$ & $45.69 \mathrm{aB}$ & $45.19 \mathrm{aA}$ & $45.67 \mathrm{aA}$ \\
December & $42.75 \mathrm{aC}$ & $41.22 \mathrm{bD}$ & $41.05 \mathrm{bB}$ & $42.73 \mathrm{aB}$ \\
January & $42.20 \mathrm{aD}$ & $41.33 \mathrm{bcC}$ & $40.45 \mathrm{cB}$ & $41.71 \mathrm{bB}$ \\
\hline Accumulated loss \% & $8.6 \%$ & $10.5 \%$ & $12.42 \%$ & $9.6 \%$ \\
\hline
\end{tabular}

Note. Equal capital letters in COLUMN do not differ from each other, at 5\% significance. Equal lowercase letters in LINE do not differ at $5 \%$ significance.

By analyzing the accumulated losses in the development it is possible to observe that the treatment that has lost the most nitrogen in urea was the treatment (CM), although the environment is statistically equal to the (EGM), however, this environment has some difference (Figure 1), because it has openings for ventilation, which allows heat dissipation. It is possible to say that this factor may have contributed to the reduction of the observed losses.

\subsubsection{Density}

The fertilizer production follows standards determined by laws and regulatory norms. In this sense, Feltran et al. (2006) state that the quality of fertilizers is influenced by their physical characteristics, such as density, size, and shape, because these are fertilizer design parameters that will determine the amount of distribution and, consequently, the performance in what concerns the distribution of granules by the implement that this application will do in the soil.

The analyses were performed in quadruplicate, at the beginning of the experiment and the end of each month, and later submitted to the Tukey test with a $5 \%$ probability.

The variation between locations and time was significant, with $(\mathrm{P}=0.0080<0.05)$, when analyzing the averages it is possible to observe that the variation was small, in relation to time the variation was not significant, but when analyzing the averages of treatment time, it is possible to note a variation of $4.5 \%$. However, concerning the interaction between local and time treatments, the following variations were observed: 
Table 8 . Detail of density between treatments time $\times$ location

\begin{tabular}{lllll}
\hline \multirow{2}{*}{ Time } & \multicolumn{3}{c}{ Location } \\
\cline { 2 - 5 } & EGM & EBM & CM & NCM \\
\hline Initial & $1.32 \mathrm{abA}$ & $1.31 \mathrm{aA}$ & $1.31 \mathrm{aA}$ & $1.33 \mathrm{cA}$ \\
November & $1.29 \mathrm{aB}$ & $1.29 \mathrm{aB}$ & $1.29 \mathrm{aB}$ & $1.30 \mathrm{aB}$ \\
December & $1.28 \mathrm{aB}$ & $1.27 \mathrm{aC}$ & $1.28 \mathrm{aC}$ & $1.28 \mathrm{aC}$ \\
Janeiro & $1.26 \mathrm{aC}$ & $1.26 \mathrm{aD}$ & $1.26 \mathrm{aD}$ & $1.26 \mathrm{aD}$ \\
\hline Accumulated loss \% & $4.5 \%$ & $3.8 \%$ & $3.8 \%$ & $5.2 \%$ \\
\hline
\end{tabular}

Note. Equal capital letters in COLUMN do not differ from each other, at $5 \%$ significance.

Equal lowercase letters in LINE do not differ at $5 \%$ significance.

From the perspective of the greatest variation, the environment (NCM) lost the highest percentage of density when analyzed from the beginning to the end of the experiment, whereas in the interval between the beginning and the end of December, the environment has the highest percentage of loss reaching up to $3.75 \%$, when compared to the others. Despite this, in December, the highest temperature in the environment was recorded (Table 8).

From the same point of view, when the variation between the beginning and the month of December is observed, the treatment $(\mathrm{EBM})$ has a loss of $3.05 \%$, the average maximum temperature was $33.2{ }^{\circ} \mathrm{C}$.

The environment (EGM) also exhibited a decrease in the density of granules close to the treatment (NCM), differentiating about $0.07 \%$, since the average maximum temperatures are very close (32.3 and 32.5), respectively.

However, when observing the highest average temperature in the interior of the environments, it was the one that occurred in the treatment (CM) in December, with a maximum average of $35.5^{\circ} \mathrm{C}$. Nonetheless, it was observed a decrease in lower density in relation to other environments, the location decreased density by $3.8 \%$, although the $\mathrm{CM}$ environment has recorded the highest average maximum temperature (Graphic 1) it can be observed that in most of the day the temperatures remain below the $25^{\circ} \mathrm{C}$ range.

With such evidence, it is not possible to state that temperature above 35.5 degrees is the triggering factor for density loss, possibly due to dilation since the nitrogen contained in the granules remains in most of the time at lower temperatures. Some manufacturers, however, relate that nitrogenates should be stored in a temperature-controlled environment in a range of 0.5 to $30.0^{\circ} \mathrm{C}$.

\subsubsection{Weight}

The variable weight can be considered an indicator of segregation, since the granules have a mass which, when lost, indicates a process of loss of substances that should be present in the granules evaluated throughout the research.

In the experiment, two $50 \mathrm{~kg}$ bags were stored, one for the collection of samples to be monitored monthly, and the other that would serve as a witness for the entire process.

The weight values related in this study, as well as the other variables, were measured at the beginning and end of each month, using a scale with an accuracy of three decimal places to left of comma. 


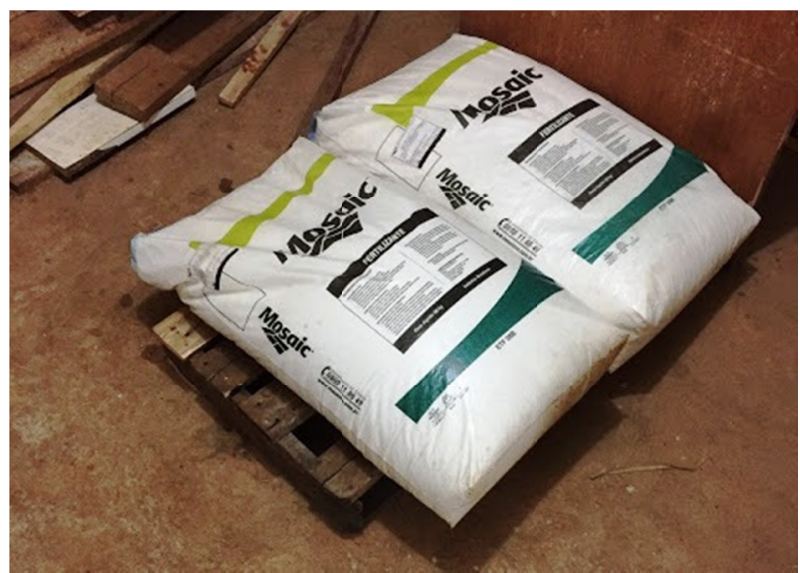

Figure 4. Bags submitted to field experiments $(50+50 \mathrm{~kg})$

The weight loss results were obtained by weighing the bag that remained closed throughout the experiment, the analysis of variance showed significant variation in the means, being $(p=0.000<0.05)$.

In the analysis performed it is possible to observe that the environment (NCM) obtained the lowest total weight loss, however, regarding the time it is possible to observe the variation from beginning to end of the experiment, $1.5 \mathrm{~kg}$, being $2.98 \%$ of the total weight of the package. Thus, it can also be verified that in relation to treatments, there was no statistical significance. However, variations occurred (Table 9).

Table 9. Total weight between storage location and time detail

\begin{tabular}{lllll}
\hline \multirow{2}{*}{ Time } & \multicolumn{4}{c}{ Local } \\
\cline { 2 - 5 } & EGM & EBM & CM & NCM \\
\hline Initial & $50.197 \mathrm{aA}$ & $50.200 \mathrm{bA}$ & $50.200 \mathrm{bA}$ & $50.200 \mathrm{bA}$ \\
November & $49.820 \mathrm{aB}$ & $49.640 \mathrm{cB}$ & $49.610 \mathrm{~dB}$ & $49.730 \mathrm{bB}$ \\
December & $49.030 \mathrm{dC}$ & $49.640 \mathrm{bB}$ & $49.610 \mathrm{cB}$ & $49.730 \mathrm{aB}$ \\
\hline January & $48.990 \mathrm{aD}$ & $48.590 \mathrm{dC}$ & $48.790 \mathrm{bC}$ & $48.680 \mathrm{cC}$ \\
\hline
\end{tabular}

Note. Equal capital letters in COLUMN do not differ from each other, at 5\% significance.

Equal lowercase letters in LINE do not differ at $5 \%$ significance.

According to the dynamics of the variation described above, it is possible to conclude that the largest accumulated losses occur in the environment (EBM), in which it is possible to find the highest accumulated average of relative air humidity and the second-highest temperature average for December. In the environment (CM) for December is found the highest maximum average temperature of $35.5^{\circ} \mathrm{C}$, but the environment has a percentage of losses lower in relation to the others. In the treatments EGM, CM, and NCM, in November and December, the losses were equal.

\subsubsection{Moisture Content}

The moisture content is directly related to the exposure of the raw material to the air relative humidity, as analyzed by Alcade et al. (1992), the excessive exposure of urea to humidity may increase the weight of the granules. However, in this study we only observed decreases in weight, because in most of the experiment time the air relative humidity in environments was slightly above the critical humidity (UC\%), being the following values of $70.4 \%, 80.5 \%$ and $77.8 \%$ exemplified by the authors.

The total averages of humidity observed in the environments were: (EGM) $71.5 \%$; (EBM) $84.4 \%$; (CM) 77.86 ; (NCM) $86.1 \%$.

The environments that had the highest value of absorbed moisture in the urea granules were (EBM) and (NCM), and in these environments they recorded the highest accumulated averages of air relative humidity, being (EBM) $84.4 \%$, (NCM) $86.1 \%$. 
The air humidity absorption is in accordance with the percentages placed by Alcade et al. (1992). The minimization of moisture absorption was decreased by the packaging in which the granules were stored.

In this sense, the results confirm that urea when exposed to critical humidity levels (UC\%) absorbs water contained in the air hygroscopic nuclei. However, the statistics did not show any significance between the locations $(\mathrm{p}=0.05>0.0000)$.

Another factor observed during the experiment is a sort of granule transpiration when modified at room temperature, apparently a process of convective change of temperature, such a factor can contribute to the formation of crystals between the granules, thus generating a possible clumping.

Table 10. moisture detail as a function of time and location

\begin{tabular}{lllll}
\hline \multirow{2}{*}{ Time } & \multicolumn{4}{c}{ Location } \\
\cline { 2 - 5 } & EGM & EBM & CM & NCM \\
\hline Initial & $0.30 \mathrm{ab} \mathrm{B}$ & $0.31 \mathrm{ab} \mathrm{C}$ & $0.30 \mathrm{cC}$ & $0.35 \mathrm{a} \mathrm{B}$ \\
November & $0.48 \mathrm{~b} \mathrm{~A}$ & $0.47 \mathrm{~b} \mathrm{~B}$ & $0.40 \mathrm{c} \mathrm{B}$ & $0.54 \mathrm{a} \mathrm{A}$ \\
December & $0.25 \mathrm{~b} \mathrm{~B}$ & $0.31 \mathrm{a} \mathrm{C}$ & $0.31 \mathrm{a} \mathrm{C}$ & $0.24 \mathrm{~b} \mathrm{C}$ \\
January & $0.52 \mathrm{a} \mathrm{A}$ & $0.54 \mathrm{a} \mathrm{A}$ & $0.52 \mathrm{a} \mathrm{A}$ & $0.54 \mathrm{a} \mathrm{A}$ \\
\hline Absorbed moisture & $73.33 \%$ & $74.19 \%$ & $73.33 \%$ & $54.28 \%$ \\
\hline
\end{tabular}

Note. Equal capital letters in COLUMN do not differ from each other, at 5\% significance.

Equal lowercase letters in LINE do not differ at $5 \%$ significance.

As described above, it is possible to observe the moisture variability absorbed by the granules, with the highest averages obtained in the last month of the experiment and the highest percentage of moisture admission was observed in the treatment (EBM), as expected. On the other hand, the EGM and NCM environments, due to their ventilation openings and facade systems, provided a drier environment; otherwise, the humidity would remain high as was observed in the treatment (EBM).

\subsubsection{Granulometry}

The results of the granulometry analysis, as well as the other variables, were performed at the beginning of the experiment and the end of each month of observation, the analyses were performed in quadruplicate, and their results were submitted to variance analysis and Tukey test with a $5 \%$ probability.

According to Feltran et al. (2006), when the granules segregation alters the granulometry, it is not possible to guarantee that all portions of the substrate will be covered by the required nutrient dose. This phenomenon can cause the distribution of the nutrient to be uneven.

Therefore, the results show that the total number of granules retained in the sieves with the passage of months suffers a decrease. Only for the $0.710 \mathrm{~mm}$ sieve, the retained content is increased by residual particles.

At first, it was expected that the fertilizer would suffer clumping until the end of the process, but what was observed was a single clumping and agglutination of the granules nearer to the closing valve of the packages. For this reason, it served as a protective barrier to the rest of the contents. 


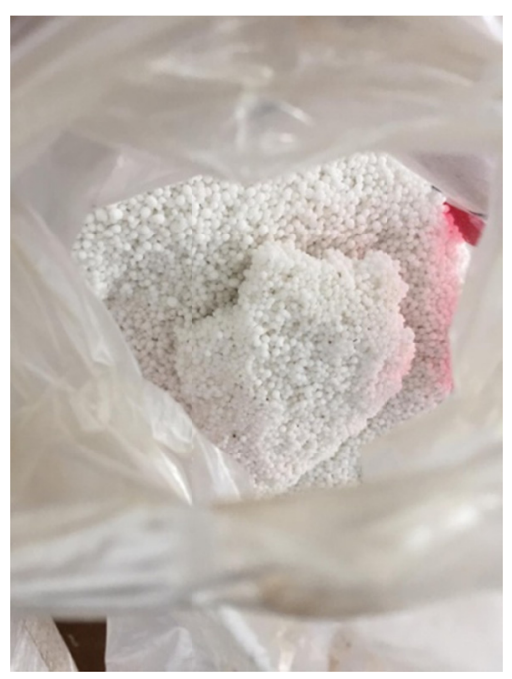

Figure 5. Fertilizer clumping near the closing valve

Thus, the following results were observed. Since this is the largest fraction of the number of granules, only the fractions with the largest quantities retained in the standardized sieves will be presented in this research. The meshes were $4.00,2.800,2.000,1.000$, and $0.710 \mathrm{~mm}$.

Table 11. Averages of variance analysis as a function of the treatments

\begin{tabular}{|c|c|c|c|c|c|}
\hline Location/Sieves (mm) & 4.000 & 2.800 & 2.000 & 1.000 & 0.710 \\
\hline EGM & $4.11 \mathrm{a}$ & $57.11 \mathrm{a}$ & $36.09 \mathrm{c}$ & $2.17 \mathrm{a}$ & $0.47 \mathrm{a}$ \\
\hline EBM & $3.25 \mathrm{c}$ & $34.30 \mathrm{c}$ & $37.76 \mathrm{bc}$ & $1.70 \mathrm{~b}$ & $0.33 \mathrm{~b}$ \\
\hline $\mathrm{CM}$ & $3.27 \mathrm{c}$ & $50.51 \mathrm{~b}$ & $39.44 \mathrm{~b}$ & $2.26 \mathrm{a}$ & $0.24 \mathrm{c}$ \\
\hline $\mathrm{NCM}$ & $3.78 \mathrm{~b}$ & $51.68 \mathrm{~b}$ & $42.51 \mathrm{a}$ & $2.31 \mathrm{a}$ & $0.30 \mathrm{~b}$ \\
\hline \multicolumn{6}{|l|}{ Time } \\
\hline initial & $3.72 \mathrm{a}$ & $49.41 \mathrm{a}$ & $41.47 \mathrm{a}$ & $2.17 \mathrm{a}$ & $0.34 \mathrm{c}$ \\
\hline November & $3.62 \mathrm{ab}$ & $49.64 \mathrm{a}$ & $39.68 \mathrm{ab}$ & $2.13 \mathrm{a}$ & $0.34 \mathrm{bc}$ \\
\hline December & $3.56 \mathrm{bc}$ & $47.89 \mathrm{bc}$ & $37.90 \mathrm{bc}$ & $2.10 \mathrm{a}$ & $0.29 \mathrm{ab}$ \\
\hline January & $3.52 \mathrm{c}$ & $46.67 \mathrm{c}$ & $37.82 \mathrm{c}$ & $2.04 \mathrm{a}$ & $0.37 \mathrm{a}$ \\
\hline TestP & \multicolumn{5}{|c|}{ 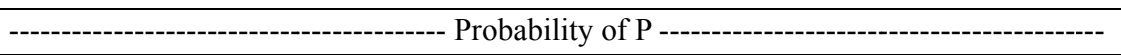 } \\
\hline Location (A) & 0.0000 & 0.0000 & 0.0000 & 0.0000 & 0.0000 \\
\hline Time(B) & 0.0128 & 0.0000 & 0.0000 & 0.1266 & 0.0094 \\
\hline $\mathrm{A} \times \mathrm{B}$ & 1.0000 & 0.3118 & 0.9855 & 0.8942 & 0.0031 \\
\hline $\mathrm{CV}(\%)$ & 4.85 & 3.40 & 4.91 & 7.69 & 17.48 \\
\hline
\end{tabular}

Note. Equal capital letters do not differ from each other, at $5 \%$ significance.

Observing the differences between the final averages of the treatments, it is possible to verify the remarkable decrease of the values as a result of time, and no decrease occurs in the sieve with the $0.710 \mathrm{~mm}$ mesh that retained powder-type residues most of the time.

For the most part, in the sieves that accumulate the highest percentages, a decrease in the accumulated percentages over the months is observed. This can be explained by the decrease in the cubic volume of the granules also observed in the density variable.

This matter is more evident when analyzing the changes in the percentages of granules separately for each of the sieves; however, the statistical tests did not indicate a significant difference, only in the $0.710 \mathrm{~mm}$ sieve, in which an increase in the accumulated residue of dust type particles was observed. 
The results observed for sieves 4,000, 2,800 and 2,000 $\mathrm{mm}$ showed no statistical difference, but when observing the percentages of losses from the beginning to the end of the observations, a similar rate of decrease is recorded.

Table 12. Percentages of granules retained in the sieve of $4.00 \mathrm{~mm}$ as a function of location and time

\begin{tabular}{lllll}
\hline \multirow{2}{*}{ Time } & \multicolumn{3}{c}{ Location } \\
\cline { 2 - 5 } & EGM & EBM & CM & NCM \\
\hline Initial & 4.25 & 3.35 & 3.40 & 3.90 \\
November & 4.15 & 3.27 & 3.27 & 3.80 \\
December & 4.07 & 3.20 & 3.22 & 3.75 \\
January & 4.00 & 3.20 & 3.20 & 3.70 \\
\hline Accumulated loss \% & $5.8 \%$ & $4.5 \%$ & $5.8 \%$ & $5.1 \%$ \\
\hline
\end{tabular}

By checking the decreases from the initial percentage to the final percentage, it is possible to note that there is a reduction of more than $6 \%$ on average of the percentages from the initial moment until the end of the experiment.

The reductions observed in $2.800 \mathrm{~mm}$ sieving were overall different from the reductions in $4.000 \mathrm{~mm}$ sieving; this detail may demonstrate different dynamics of segregation. For the percentages retained in $2.0 \mathrm{~mm}$ sieving, there was no statistical significance, since the value of $(P=0.9855>0.05)$. Thus, there was no interaction between treatments.

The accumulated granule losses in 2,000 $\mathrm{mm}$ sieves have similarities between the treatment (EBM) and (CM) since they vary the same amount as a function of time.

For the accumulated content of the 0.710 sieves, an increase in the number of residues as a function of time was noted. This may indicate a degrading process of the granules, because the retained content has an aspect of peels and dust, in small quantities. Thus, the results prove that urea suffers a decrease in its cubic area, compromising the distribution uniformity, as has been reported by the authors who also investigate the subject.

\section{Discussion}

It is empirical knowledge that urea undergoes mutations in the face of climatic hostilities, such as high temperatures and excessive humidity in the air. Therefore, considering the lack of specific knowledge in this area, the present study has as one of its objectives to verify under what conditions the urea undergoes a greater process of physical and chemical degradation that subsequently compromises its performance in the field. In this way, such results are discussed.

The EGM and CM treatments had, on average, the same behavior in relation to the internal temperature averages during the period of the experiment. However, the CM treatment lost $13.07 \%$ of nitrogen, while the EGM treatment lost slightly less, accumulating a total of $8.6 \%$. Such acceleration of loss is believed to have occurred because the CM treatment did not have openings for ventilation, and, consequently, for heat dissipation as there was in the EGM treatment, which has openings with constant ventilatory flow. Such heat loss is quantified and explained in this work (Tables 3, 4, and 5). In those tables, the heat losses in watt $/ \mathrm{m}^{2}{ }^{\circ} \mathrm{C}$ that the building suffers when the external temperature becomes lower in relation to the internal condition were also analyzed. This process is most commonly observed at night.

From the point of view of density, the treatments EGM and CM had practically the same amount of density loss. The greatest loss possibly occurred where there was a greater ventilation flow, that is, the treatment EGM. The highest frequency of hardening and agglutination occurred in environments of higher temperatures and higher relative humidity, where a process of convection of humidity was observed nearthe valves for closing the bags.

All packages submitted to the experiment were weighed at the beginning and at the end of each month of the experiment. The treatments EGM and CM showed a variation of up to $2 \%$ of the weight during the experiment. EGM suffered greater ventilation and, consequently, less heating of the volume of raw material contained in the packaging.

\section{Conclusions}

The conclusion of the present study is that urea has a strong physical chemical sensitivity, and this characteristic generates problems to the manufacturing pattern which will condition a deficiency in the performance of the fertilizer. However, the conclusion to be considered as the scientific contribution to the storage of the fertilizer is 
to keep it in a cool and airy place, onceit will reduce the irradiation of heat incident on the packaging of the agricultural input.

Another conclusion in relation to storage buildings is the organization of the architectural layout in order to generate closing walls that are shaded in the spatial orientations of greater incidence of sun, which added to the opening devices for ventilation positioned in the direction of the prevailing wind will cause the building to decrease the gain due to thermal delay, when the external temperature is lower than the internal temperature.

\section{References}

ABNT (Associação Brasileira de Normas Técnicas). (2003). NBR 15220-2: Desempenho térmico das edificações. Parte 2: Métodos de calculo da transmitancia térmica de cálculo da tramitância térmica, da capacidade térmica, do atraso térmico e do fator solar de elementos e componentes de edificações. Rio de Janeiro, RJ: ABNT.

Alcade, J. C., Malavolta, E., Borges, A. L., Muniz, A. S., Veloso, C. A., Fabricio, A. C., \& Viegas, I. de J. M. (1992). Avaliação de higrospicidade de fertilizantes e corretivos. Scientia Agricola, 49(SP), 137-144. https://doi.org/10.1590/S0103-90161992000400018

Carvalho, J. P. (1995). Fatores de variação de analise quimica e granulometrica de fertilizantes. ESALQ-USP. Retrieved from http://teses.usp.br/teses/disponiveis/tde20181127-160342/publico/CarvalhoFernandoJosePe reiraCampo.pdf

Contreiras, A. P., Yamamoto, C. R., Feitas, M. E., \& Bono, J. A. (2008). Modo de aplicação de fertilizantes nitrogenados na qualidade fisiológica de sementes de milho. Agrarian Journal. Retrieved from https://ojs.ufgd.edu.br/index.php/agrarian/article/views/258/210

Embrapa (Empresa Brasileira de Pesquisa Agropecuária). (2013). Determinação de nitrogenio em fertilizantes nitrogenados utilizando dois metodos (Technical Report). Embrapa, Brazil.

Feltran, J. C., Corrêa, J. C., Brancalião, S. R., \& Vilas Boas, R. L. (2006). Segregação física e química dos fertilizantes formulados. Cientifica, 34(2), 188-196. https://doi.org/10.15361/1984-5529.2006v34n2 p188+-+196

Frota, A. B. (2004). Geometria da Insolação (1st ed.). São Paulo, Brasil: Geros.

Lamberts, R., Dutra, L., \& Pereira, F. O. (2014). Eficiência Energética na Arquitetura. SãoPaulo, Brazil: PW Editores.

MAPA (Ministério da Agricultura, Pecuária e Abastecimento). (2014). Manual de métodos analiticos oficiais para fertilizantes e corretivos. Retrieved from https://www.gov.br/agricultura/pt-br/assuntos/laboratorios/ legislacoes-e-metodos/fertilizantes-substratos/manual-de-metodos

Michels., C. (2007). Analise das trasferencias de calor em coberturas com barreiras radiantes (Master's thesis, Graduate Program in Civil Engineering, Universidade Federal de Santa Catarina, Brazil).

Tasca, F. A., Ernani, P. R., Rogeri, D. A., Gatiboni, L. C., \& Cassol, L. C. (2011). Volatilização de amonia do solo após aplicação de ureia convencional ou com inibidor de urease. Brazilian Journal of Soil Sciences, 35, 493-502. https://doi.org/10.1590/S0100-06832011000200018

\section{Copyrights}

Copyright for this article is retained by the author(s), with first publication rights granted to the journal.

This is an open-access article distributed under the terms and conditions of the Creative Commons Attribution license (http://creativecommons.org/licenses/by/4.0/). 